\title{
The Mechanism and Development Strategies of CTGU Teaching Supervision-The College of Electrical Engineering \& Renewable Energy Case
}

\author{
Jiuyan Zhou ${ }^{1}$
}

The College of Electrical Engineering \& renewable Energy, The Three Gorges University, Yichang, China

\section{3@qq.com}

Keywords: Colleges and universities; personnel training; Teaching Supervision; operating mechanism

\begin{abstract}
In order to supervise the supervisors to position their role, to carry out the function more effectively, and to help teachers promote teaching level, and scientific research and teaching reform, in this paper, a systematic analysis method, operation of external study from a teaching mechanism and external quality supervision environment, supervision of internal inspection will be teaching input elements operating mechanism, operation elements, output elements and feedback elements of four basic elements and relationships, to identify our teaching supervision mechanism in the four elements of the problems raised on this basis the relationship between the environment from the system and provide. And propose that the supervisors should transform their roles from the supervision to the guidance, and fully exert their roles to promote teaching team building in the universities.
\end{abstract}

\section{Introduction}

Teaching supervision is an activity organized to improve the quality of teaching and conduct, and its mission is to improve the teaching quality of teachers choose teaching materials and organize lesson plans, assessment of teaching effectiveness, improve teaching standards and evaluation of teachers.

Teaching supervision plays a positive role in checking, supervising and guiding classroom teaching quality. After over one decade's practice and exploration, the teaching supervision work of the writer's university has achieved satisfactory effect in improving education mechanism, deepening teaching reform and controlling teaching operation. However, there are still many problems in practical teaching supervision work, so the team of teaching supervision should be perfected, the content and scope of work should be expanded, and the strengthening of guidance and feedback should be continued. Combined with the practical situation of the writer's university, this paper analyzes the current situation and existing problems of teaching supervision, and studies countermeasures to improve the effectiveness of teaching supervision.[1][2]

University teaching supervision workflow shown in Fig.1

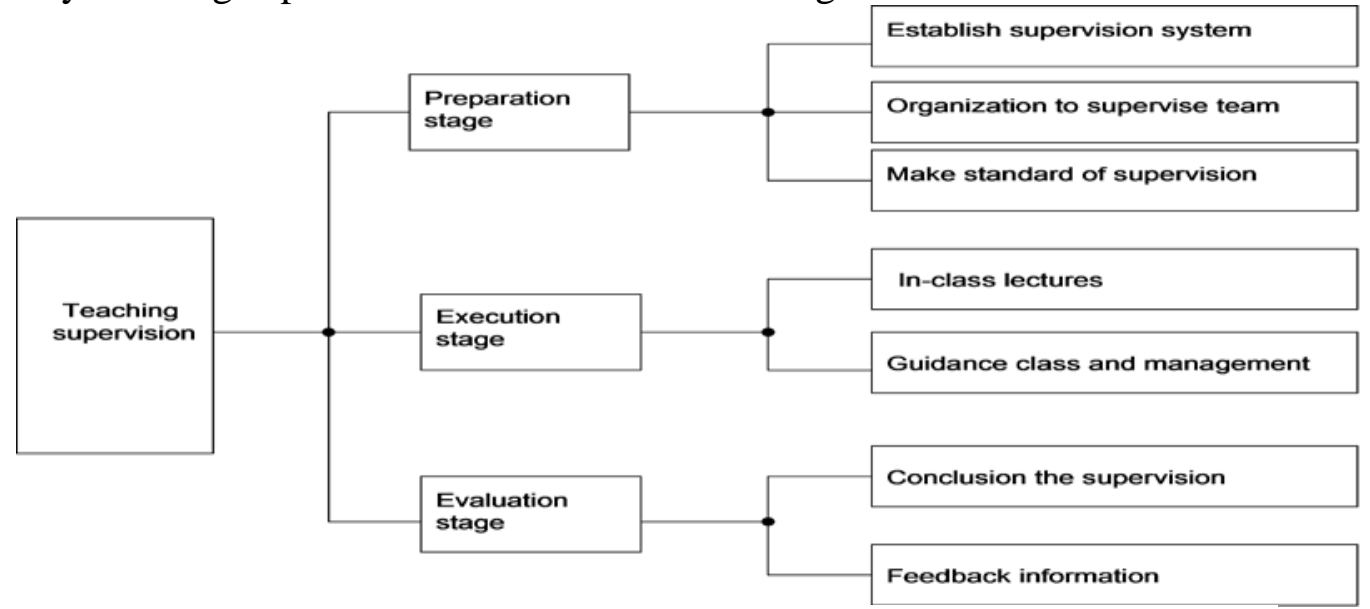

Fig.1 University teaching supervision operation mechanism workflow 


\section{Teaching Supervision Status and Analysis of Our School}

Our school teaching supervision organized by the two-level components: university and college teaching supervision. They were on the order of teaching in schools and colleges, teaching quality, teaching management and work status supervision. Shown in Fig. 2

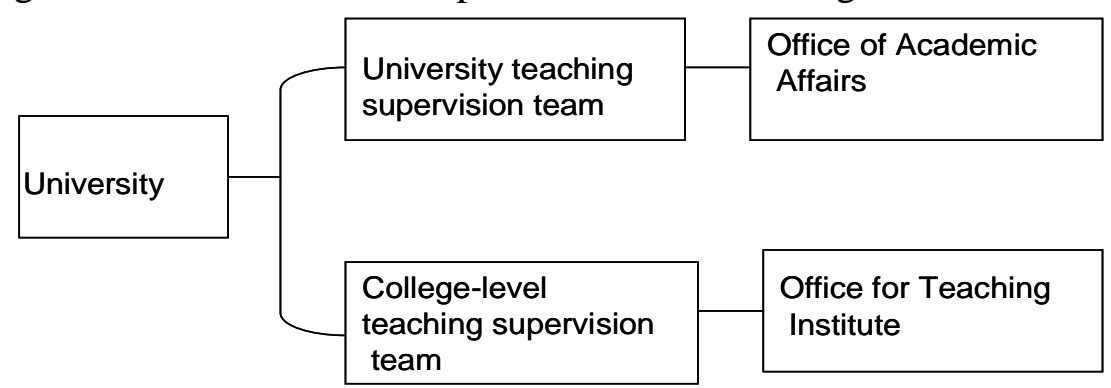

Fig. 2 Two levels of teaching supervision

I served as a college teaching supervisor from 2008, in the implementation process, the contents of teaching supervision is undoubtedly the most important aspect. Previous supervision is to classroom performance of teachers, mostly related to teaching content, teaching methods, for problem students learning state, hardware conditions and other aspects of teaching despite the attention. In 2014, Our college issued new rules for teaching supervision, teaching supervision group changed its name to the teaching committee, Increase the scope of its functions. Everything to do with teaching decisions is decided by the teaching committee.

\section{The Main Problems in the Teaching Supervision}

\subsection{Teaching quality standard is not unified}

Supervisor will fill a table each class, as shown in table 1.

Table 1 Evaluation score sheet

\begin{tabular}{|c|l|l|l|l|}
\hline $\begin{array}{c}\text { Level } 1 \\
\text { indexes }\end{array}$ & $\begin{array}{c}\text { secondary } \\
\text { indexes }\end{array}$ & $\begin{array}{c}\text { contents and } \\
\text { standards }\end{array}$ & $\begin{array}{c}\text { secondary } \\
\text { score }\end{array}$ & Level 1 score \\
\hline $\begin{array}{c}\text { Morality and } \\
\text { demeanor }\end{array}$ & $\ldots$ & $\ldots$ & $?$ & $?$ \\
\hline $\begin{array}{c}\text { Teaching } \\
\text { specification }\end{array}$ & $\ldots$ & $\ldots$ & $?$ & $?$ \\
\hline Teaching status & $\ldots$ & $\ldots$ & $?$ & $?$ \\
\hline $\begin{array}{c}\text { Teaching } \\
\text { characteristic }\end{array}$ & $\ldots$ & $\ldots$ & $?$ & $?$ \\
\hline Student status & $\ldots$ & $\ldots$ & $?$ & $?$ \\
\hline
\end{tabular}

Evaluate the state of classroom teaching quality, the standard when there is no scientific basis, it is difficult to evaluate objectively the accurately and ratings, personal subjective evaluation error will cause damage to the interest of teachers objectively, Quality standards for arbitrary to fair evaluation.

\subsection{The effect of teaching supervision in colleges needs to be improved.}

Colleges and universities teaching supervision mechanism is shown in fig. 3 


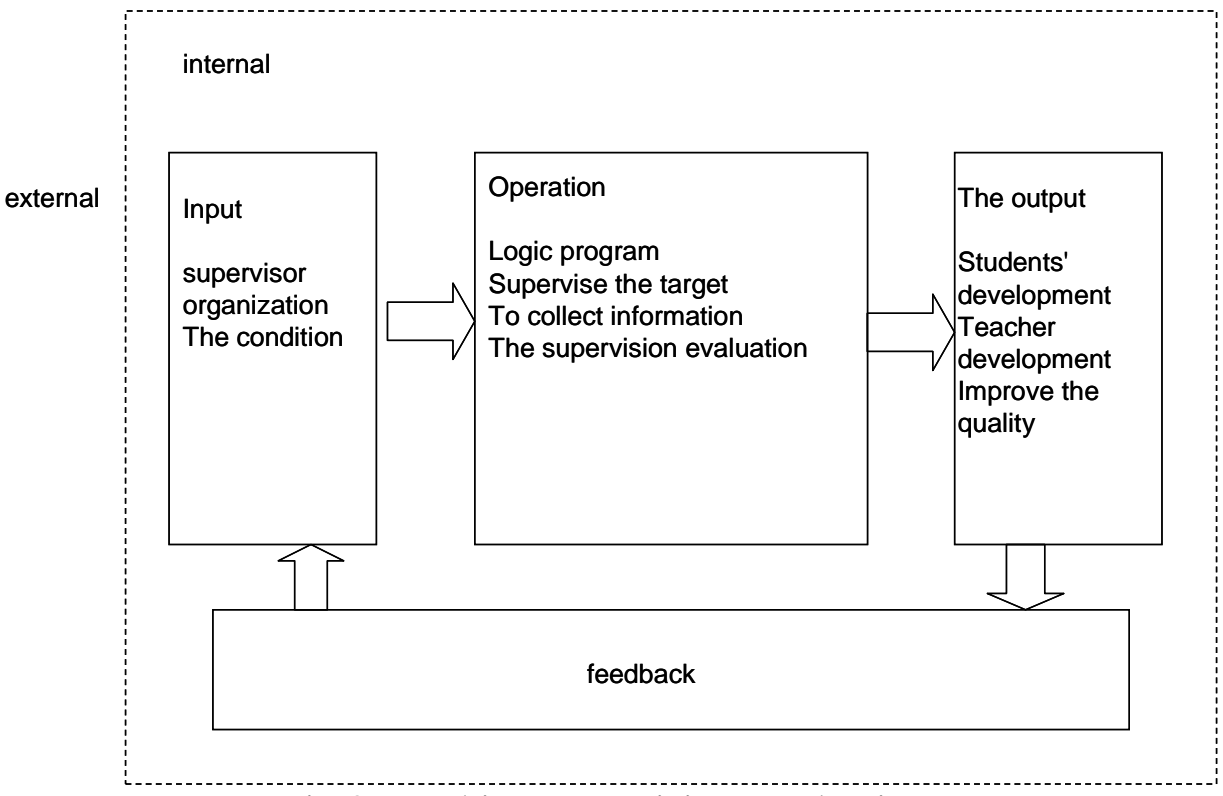

Fig.3 Teaching supervision mechanism

On the current status, the feedback on classroom teaching ranks large, the lack of multi-level and multi-form feedback. In terms of feedback content, is a lesson in teacher's performance, and can't reflect the reality of the teacher level. In terms of feedback channel, the micro level, the lack of the macro level. Supervision environment is not harmonious, hard to wield the supervision function.[3] [4]

\section{Suggestions}

\subsection{To establish a complete system of teaching supervision in colleges.}

Quality is a basic concept of education output from member of the school and personally. Currently, the university is moving from quality management based on the quality of management data, based on the quality of management information, based on the quality of management to the quality of education and services continue to improve the quality of knowledge and improvement. most teachers don't know much about teaching supervision in colleges, teaching supervision should be divided into two teaching monitoring system, college-level teaching hospital teaching committee responsible for inspection, Each department is responsible for the teaching supervision to inspect and guide the work of the department of education, the department of teaching supervision department members familiar with the situation, understanding of the professional knowledge, familiar with the instructor, teaching better inspection and guidance. Both levels of teaching supervisors in accordance with their own way to work, to exercise the functions of each other. [5] [8]

\subsection{Improve the effect of teaching supervision.}

University decision system, teaching supervisors, teachers, configured as shown in Fig.4

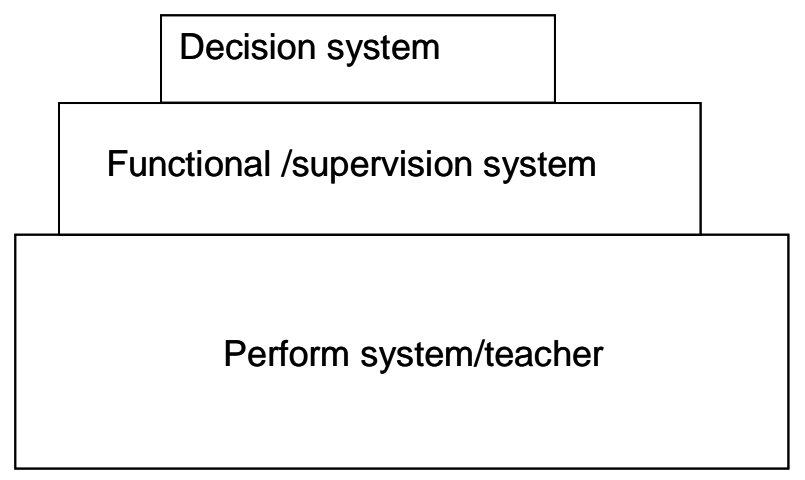

Fig.4 Model of teaching supervision organizational structure 
Teaching quality management is a system, including the decision-making subsystem, subsystem functions, teaching supervision subsystem. Decision-making subsystem is the school teaching committee, responsible for school orientation and quality standards, responsible for teaching evaluation, students' quality evaluation method, the teaching management level and so on. Office of academic affairs is the intelligent subsystem, including university teaching supervision, responsible for teaching undergraduate and graduate teaching management decisions, the functions of the system to deal with the supervision system plays a coordinating role. Execution system is the college. Perform system for knowledge transfer and innovate, supervise the effective fulfillment system make management strategy of the decision system, Decision-making body for the basic direction. Form a perfect teaching quality management system.[3],[9]

\section{Conclusion}

Nowadays, colleges and universities are laying a special emphasis on teaching qualities. Under this background, this paper explores the strategies and approaches to building a system for monitoring teaching qualities at secondary colleges, according to the characteristics of undergraduate education for application-oriented universities and colleges. It is proposed that teaching quality monitoring be guaranteed by employing measures such as monitoring teaching, monitoring learning and building rapid feedback mechanism. The teaching practice shows that teaching quality monitoring system at secondary colleges plays a positive role in improving the ability of teaching and effect of learning and it is a feasible way to improve the quality of cultivation of talents.

\section{References}

[1]. Shang Hui, On Effective Implementation of Teaching Supervision and Improvement of Classroom Teaching Quality, [J], The Science Education Article Collects, January 2015.(In Chinese)

[2]. MA Wending, HUANG Jian, [J], Research Summary of Teaching Supervision in China's Universities, JOURNAL OF CHANGCHUN UNIVERSITY, Dec. 2013 .(In Chinese)

[3]. HU YAN-LING, Research Teaching Supervision Operation Mechanism of Chinese Universities, MASTER'S THESIS, 2010.(In Chinese)

[4]. ZOU MENG, TANG XU-DONG, Combination of Management, Assessment, Supervision and Guidance to Upgrade Teaching Quality, [J],TOURNAL OF NINGBO UNIVERSITY OF TECHNOLOGY, Vo1.25 No.l Mxr2013.(In Chinese)

[5]. WU Kai-dong, GONG Neng-ping, On the Establishment and Practice of the Teaching Quality Security and Supervision System in the Credit System, [J], Journal of Anhui University of Technology (Social Sciences), Vol .30,November No . 6, 2013.(In Chinese)

[6]. WANG Yon, Study on the Teaching Quality Supervision and Guarantee System within Universities, [J], Journal of Qiqihar University(Phi\& Soc Sci), March 2013 .(In Chinese)

[7]. JIN Tao, ZHU Zuo-bin, Roles and Relations of the Three-level University Teaching Supervision Management [J], JOURNAL OF NINGBO UNIVERSITY (EDUCATIONAL SCIENCEEDITION), Mar 2013.(In Chinese)

[8]. ZHAO Shu, LIU Xiaoman, Research on Construction of Curriculum Computer Organization and Architecture Facing Engineering Education Professional Accreditation,[J], Journal of Hefei Normal University May. 2015.(In Chinese) 
[9]. WAND Qi, WAND Yi-qun, On the Construction of Teaching Supervision System at Secondary Colleges Application-Oriented Universities, [J], Journal of Nanjing Institute of Technology (Social Science Edition Jun. ,2015.(In Chinese) 